\title{
ASSESSMENT OF ARCH LENGTH PREDICTION BASED ON CBCT MEASUREMENTS OF INTER-CANINE WIDTH IN EGYPTIAN POPULATION SAMPLE; A RETROSPECTIVE STUDY
}

Engy Ali Abdelhaleem Salam*, Hanem Y. El-Feky ${ }^{* *}$ and Ayman Raouf Khalifa***

\begin{abstract}
Background: Dental arch length, width, and perimeter were important keys for diagnosis and treatment of orthodontic cases. Cone beam computed tomography (CBCT) can provide precise measurements of arch width and tooth dimension. Aim of our study was to find the reliability of Paulino et al's and Vaishnav et al's regression equations and to investigate the arch length prediction from inter-canine arch width in samples of Egyptian population based on CBCT software measurements in both upper and lower arches and in both genders .
\end{abstract}

Material and Methods: The study was carried out on 60 patients who visited the department of oral and maxillofacial radiology, Fayoum University for dental treatments. The study sample were grouped into two groups, group A (30 males) and group B (30 females) aged between 18-25 years old. CBCT examination was performed for all patients. Upper and lower arches were selected for linear measurements using CBCT including ( ICW, IMW, ISMW, ADM, ADD and AL) and a regression equation was used to predict the arch length based on ICW measurements and correlate it to actual linear measured arch length from CBCT samples of male and female groups

Results: There was a highly significant difference at p-value (0.01) between Male, and Female for ICW and AL in both mandible and maxilla, for the benefit of the male sample. There was statistically significant difference of predicted $\mathrm{Al}$ using two regression equations formula used in Non-Egyptian population with the original arch length obtained from CBCT linear measurements.

Conclusion: The regression equation formulae was not reliable to predict arch lengths, so we developed a new regression equation for Egyptian population in maxillary and mandibular arch for male and female.

KEYWORDS: CBCT, Arch width, Arch length prediction, Regression equation, sexual dimorphism

\footnotetext{
* Lecturer, Oral Radiology Department, Faculty of Dentistry, Fayoum University

** Lecturer, Department of Orthodontics, Faculty of Dentistry, Fayoum University, Egypt.

*** Lecturer, Department of Pedodontics and Orthodontics, Faculty of Dentistry, October 6 University.
} 


\section{INTRODUCTION}

During orthodontic treatment planning, it is critical to evaluate tooth measurements and dental arch relationships. For this reason, plaster model (PM) which obtained from classic dental impression has been widely used. ${ }^{[1]}$ Plaster model production necessitates a large storage spaces and comes with high risk of damage which could results in the loss of patient records. PM must be replicated and mailed, in case of multidisciplinary uses by many clinicians, raising the possibility of distortion with more cost and time. Moreover, plastic models have disadvantage related to volumetric deformation which can lead to measurements errors [2-5] consequently, finding a viable alternative to such models is of great importance. ${ }^{[6]}$

In the late 1990s, the development of CBCT was a significant achievement as it gives a 3D digitalized image make it useful in orthodontic diagnosis..$^{[7,8]}$ The use of CBCT images has increased in many clinical applications to observe the maxillofacial region as Cone-beam devices can provide images with submillimeter resolution and good diagnostic quality, with a short scanning time and radiation dosages up to several times lower than those of conventional CT scans. ${ }^{[8,9]}$

With the help of CBCT software, orthodontist can work on tooth sizes and arch dimensions measurements from digital diagnostic simulation models (DDS) either by scanning the dental cast or intraoral scanning or obtaining these measurements directly from 3D CBCT images. CBCT enables the determination of tooth size and arch dimension as fast, reliably, correctly, and consistently as possible when compared to measurements acquired using the Digital Method on digitalized plaster models..$^{[6,8,10]}$

Comprehensive orthodontic treatment goals were to obtain good occlusion with normal overbite, overjet and good esthetic ,and stability of teeth. ${ }^{[1]}$

Expectation of the change in arch length in relation to different arch width could be considered in space analysis and in designing of the dental arch expansion, for proper treatment planning and to have stable orthodontic retention. Also, prediction of arch length makes task simpler in case of missing of teeth and during tooth developments. ${ }^{[12]}$

The anterior portion of the dental arch expands more than the posterior portion during maxillary sutural expansion, according to many clinicians, and this is likely due to the resistance of zygomatic buttresses, others have noticed that the mandibular arch growth follow the expansion of maxillary arch due to the effect of occlusion and changes in the extraoral tissue drape.$^{[13,14]}$

Some studies have been done to predict the arch length based on intercanine and intermolar width (ICW, IMW) ${ }^{[14-16]}$. Paulino et $\mathrm{a}^{[15]}$ have given a regression equation for predicting the $\mathrm{AL}$ of upper and lower arch based on ICW in Spanish population, while Vaishnav et $\mathrm{al}^{[14]}$ established new formula for North Gujarat population to predict AL from ICW for each arch.

Many studies have been conducted to investigate the dental arch dimensions and relationships in different ethnicities and different geographical areas ${ }^{[17-20]}$ thus, the aim of our study was to find the reliability of Paulino et al's and Vaishnav et al's regression equations and to investigate the arch length prediction from inter-canine arch width in samples of Egyptian population based on CBCT measurements.

\section{MATERIALS AND METHODES}

The present study was carried on 60 patients who visited the oral and maxillofacial radiology department, Fayoum University for purposes rather than the study. The study sample were grouped into two groups, group A (30 males) and group B (30 females) aged between 18-25 years old.

Ethical approval was granted by the Ethics Committee of the faculty of Dentistry, October 6 University (RECO6U/11-2020), and informed consent was obtained from all subjects. 
Subjects were selected according to the following inclusion criteria

1. All the subjects were classified as Angle's class I molar and canine relationships, With minor crowding (less than $3 \mathrm{~mm}$ ). ${ }^{[21]}$

2. All had permanent dentition from second molar to second molar without gingival overlapping on the surface of any tooth (no gingival enlargement).

3. The teeth had no evident loss of mesio-distal crown width due to dental caries, crown fracture, pathological wear, or congenital defects.

4. No previous history of orthopedic, orthodontic, or orthognathic surgery.

5. No cross bite or open bite malocclusion .

6. No previous orthodontic treatment, nor congenital and craniofacial defects such as cleft lip and palate.

\section{Landmarks identification}

The Cone Beam Computer Tomography (CBCT) Device used in the present study was Planmeca, Promax 3D Max, Finland, with the following acquisition parameters: All scans were output with 512 X 512 pixels per slice and 8 bits

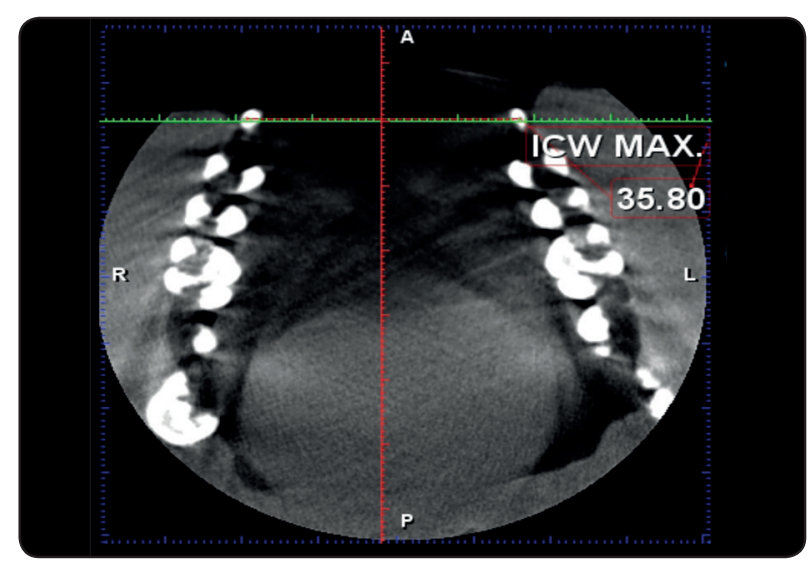

Fig. (1): CBCT axial cut showing upper inter-canine width, linear measurements were taken between the cusp tip of upper right and left canines per pixel. Resultant voxels were isotropic having identical length, width and depth of $0.16 \mathrm{~mm}$. The acquisition time for each slice was 12 seconds and the reconstruction time was 60 seconds at an angular increment of 0 degrees.

\section{Arch measurements include}

1. Inter canine width (ICW): upper and lower intercanine distance( UICW, LICW), linear measurements were taken between the cusp tip of right and left canines of the same arch on axial CBCT slice and verified on the coronal cut. (fig $1,2)$

2. Inter-first molar Width (IMW): upper and lower intermolar distance (UIMW, LIMW) linear measurements were taken between the mesiobuccal cusp tip of one first permanent molar from right side to left side on axial CBCT slice and the measurements verified on coronal cut. (fig 3,4$)^{[6]}$

3. Inter-second molar Width (ISMW): upper and lower inter-second molar distance (UISMW, LISMW) linear measurements were taken between the disto-buccal cusp tip of one second permanent molar from right side to left side on axial CBCT slice and the measurements verified on coronal cut.

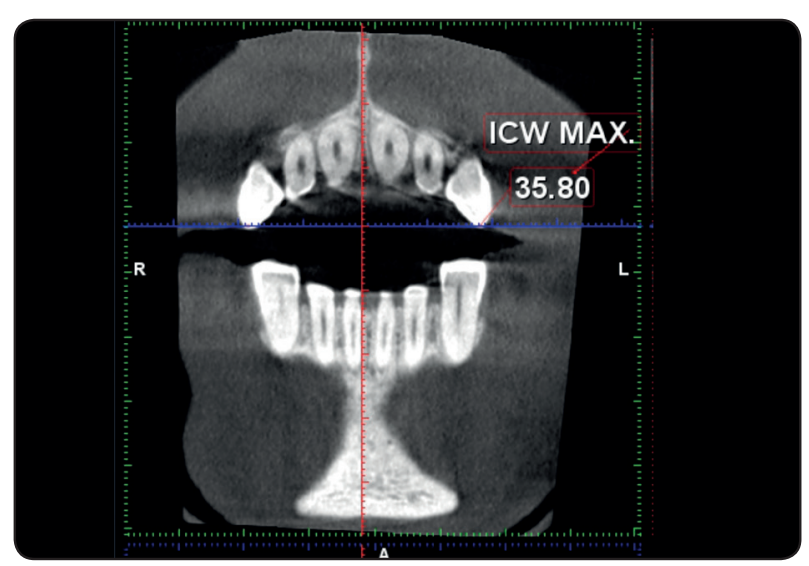

Fig. (2): CBCT coronal cut showing inter canine width, linear measurements were taken between the cusp tip of upper right and left canines to verify the measurements taken on the axial. 
4. Arch depth1 (ADM): The vertical distance from the mesial contact point of central incisors and end upon intersecting Inter molar width (linear measurements that were taken between the mesio-buccal cusp tips of both first permanent molars).(fig 3 )

5. Arch depth2 (ADD): The vertical distance from the mesial contact point of central incisors and end upon intersecting Inter-second molar width (linear measurements that were taken between the disto-buccal cusp tips of both second

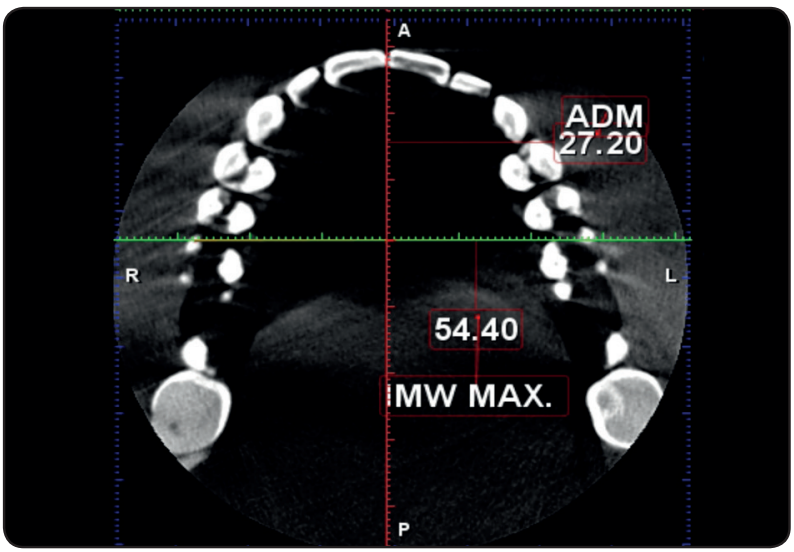

Fig. (3): CBCT axial cut showing upper Inter-first molar Width (IMW MAX.) and upper Arch depth1 (ADM).

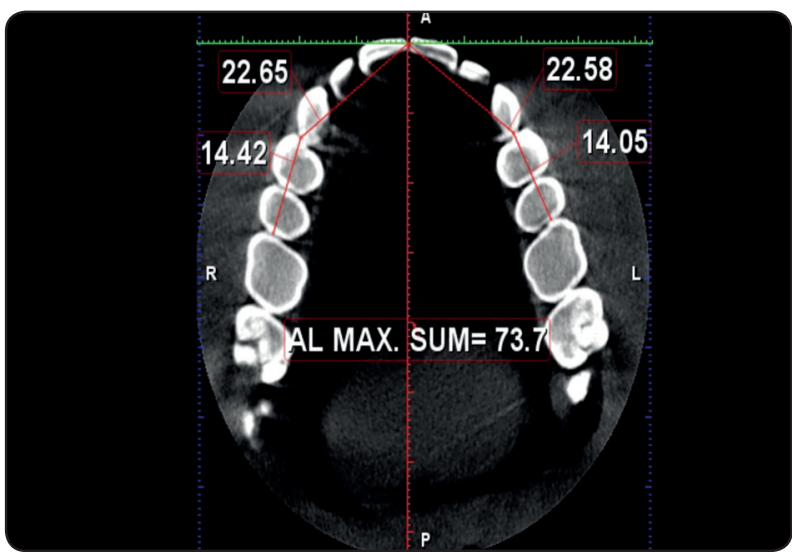

Fig. (5): CBCT axial cut showing upper Arch length (AL MAX.): the sum of fragmental lines from right and left side of the arch permanent molars).

6. Arch length (AL): the original upper and lower arch length is the sum of fragmental lines from right and left side of the arch. (fig 5,6) These segments are starting from the mesial contact of the 1st molar to the distal contact point of the canine and after here to the contact point of the central incisors. ${ }^{[8,14]}$

The examiners were allowed to scroll up and down the CBCT axial images to pick the slice that provided better visualization of each point.

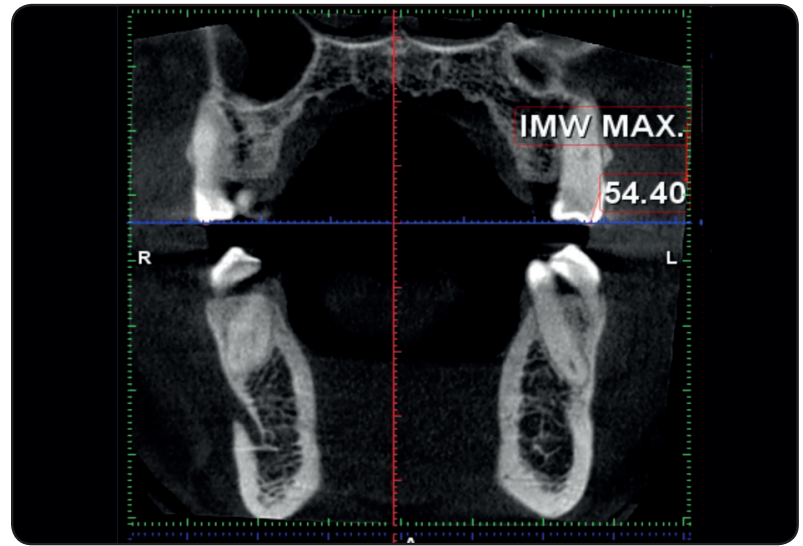

Fig. (4): CBCT coronal cut showing upper Inter-first molar Width (IMW MAX.) linear measurements were taken between the mesiobuccal cusp tip of upper first permanent molar from right side to left side.

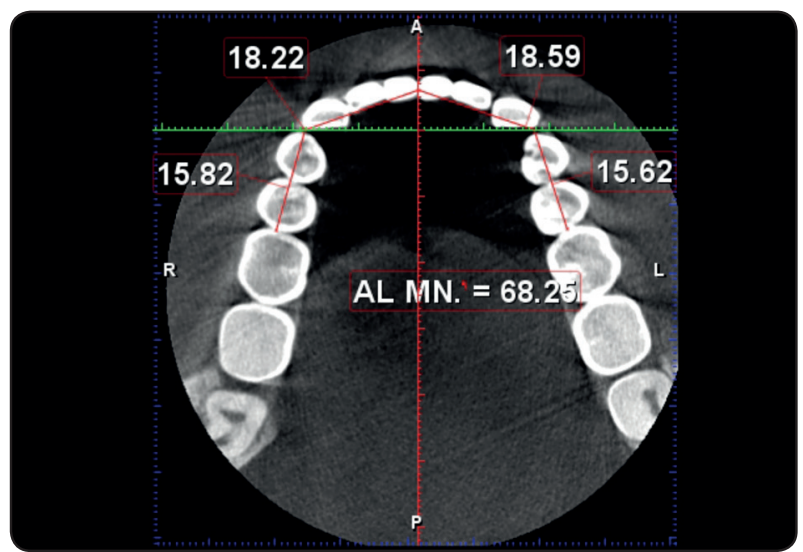

Fig. (6): CBCT axial cut showing lower Arch length (AL MN.): the sum of fragmental lines from right and left side of the arch 


\section{Calculated parameters}

- The calculated (predicted) AL of both upper and lower arches was obtained from calculation based on the linear regression equation given by Paulino V. et $\mathrm{al}^{[15]}$.

The regression equation states that $\mathrm{AL}$ in $\mathrm{mm}=$ $1.36 \mathrm{ICW}+29.39$.

- Also we used Vaishnav et al ${ }^{[14]}$, new formula for North Gujarat population to calculate AL, The equation was:

Upper AL= $48.193+0.751$ (Inter Canine Width Upper)

Lowe $\mathrm{AL}=51.727+0.440$ (Inter Canine Width Lower)

\section{Statistical analysis of survey methods:}

60 patients (30 male, 30 female) were selected. Data were unloaded by known SPSS V. 25 and through it, we used the following tests: T- Test to illustrate the differences between the study sample \& Simple regression analysis was also being done to analyze the applicability of the linear regression equation for predicted arch length and measured arch length.

\section{RESULTS}

From the table (1) showed the differences between the study sample according to Gender of Mandible as the following:

- There was a highly significant difference at pvalue (0.01) between (Male) and (Female) for (ICW) where (T) value was (4.689) with p-value (0.001), the mean of (Male) (27.87) and the mean of (Female) (25.53) for the benefit of the male sample.

- There was a highly significant difference at p-value (0.01) between (Male) and (Female) for (AL) where $(\mathrm{T})$ value was $(3.827)$ with $\mathrm{p}$-value $(0.001)$, the mean of (Male) (64.2) and the mean of (Female) (60.39) for the benefit of the male sample.

- There was non-significant difference at $\mathrm{p}$-value (0.05) between (Male) and (Female) for (IMW $\left.1^{\mathrm{ST}}\right)$ where $(\mathrm{T})$ value was $(0.207)$ with $\mathrm{p}$-value (0.8), the mean of (Male) (42.87) and the mean of (Female) (42.33).

- There was a highly significant difference at pvalue (0.01) between (Male) and (Female) for (IMW $2^{\mathrm{ND}}$ ) where $(\mathrm{T})$ value was $(8.013)$ with p-value (0.001), the mean of (Male) (57.49) and the mean of (Female) (51.32) for the benefit of the male sample.

TABLE (1): T- Test to illustrate the differences between the study sample according to Gender of Mandible and Maxilla

\begin{tabular}{|c|c|c|c|c|c|c|c|c|c|c|c|c|}
\hline \multirow{4}{*}{$\begin{array}{l}\text { Variable } \\
\mathrm{ICW}\end{array}$} & \multicolumn{6}{|c|}{ MANDIBLE } & \multicolumn{6}{|c|}{ MAXILLA } \\
\hline & \multirow{2}{*}{\multicolumn{2}{|c|}{$\begin{array}{c}\text { Male }(n=30) \\
\text { Mean } \pm \text { SD }\end{array}$}} & \multirow{2}{*}{\multicolumn{2}{|c|}{$\frac{\text { Female }(n=30)}{\text { Mean } \pm \text { SD }}$}} & \multirow{3}{*}{$\begin{array}{c}\mathbf{T} \\
4.689\end{array}$} & \multirow{3}{*}{$\begin{array}{c}\text { P-value } \\
0.001 \mathrm{HS}\end{array}$} & \multirow{2}{*}{\multicolumn{2}{|c|}{$\begin{array}{c}\text { Male }(n=30) \\
\text { Mean } \pm \text { SD }\end{array}$}} & \multirow{2}{*}{\multicolumn{2}{|c|}{$\frac{\text { Female }(n=30)}{\text { Mean } \pm \text { SD }}$}} & \multirow{3}{*}{$\begin{array}{c}\mathbf{T} \\
6.181\end{array}$} & \multirow{3}{*}{$\begin{array}{l}\text { P-value } \\
0.001 \mathrm{HS}\end{array}$} \\
\hline & & & & & & & & & & & & \\
\hline & 27.87 & 2.36 & 25.53 & 1.37 & & & 36.43 & 2.38 & 33.36 & 1.30 & & \\
\hline $\mathrm{AL}$ & 64.20 & 3.69 & 60.39 & 4.00 & 3.827 & $0.001 \mathrm{HS}$ & 73.65 & 3.33 & 69.38 & 4.07 & 4.448 & $0.001 \mathrm{HS}$ \\
\hline IMW $1^{\mathrm{sT}}$ & 42.87 & 14.15 & 42.33 & 1.90 & 0.207 & $0.8 \mathrm{NS}$ & 55.07 & 2.28 & 49.61 & 2.25 & 9.343 & $0.001 \mathrm{HS}$ \\
\hline IMW $2^{\mathrm{ND}}$ & 57.49 & 3.86 & 51.32 & 1.70 & 8.013 & $0.001 \mathrm{HS}$ & 61.77 & 4.44 & 55.29 & 2.74 & 6.796 & $0.001 \mathrm{HS}$ \\
\hline $\mathrm{ADM}$ & 23.12 & 1.76 & 21.88 & 6.84 & .960 & $0.3 \mathrm{NS}$ & 27.50 & 1.82 & 26.80 & 2.73 & 1.182 & $0.3 \mathrm{NS}$ \\
\hline ADD & 35.17 & 7.16 & 33.59 & 6.77 & .873 & $0.4 \mathrm{NS}$ & 40.79 & 4.22 & 40.65 & 4.23 & 0.128 & $0.4 \mathrm{NS}$ \\
\hline
\end{tabular}


- There was non-significant difference at p-value (0.05) between (Male) and (Female) for (ADM) where $(\mathrm{T})$ value was $(0.960)$ with p-value $(0.3)$, the mean of (Male) (23.12) and the mean of (Female) (21.88).

- There was non-significant difference at p-value (0.05) between (Male) and (Female) for (ADD) where $(\mathrm{T})$ value was $(0.873)$ with $\mathrm{p}$-value $(0.4)$, the mean of (Male) (35.17) and the mean of (Female) (33.59).

From the table (1) showed the differences between the study sample according to Gender of Maxilla as the following:

- There was a highly significant difference at $\mathrm{p}$ value (0.01) between (Male) and (Female) for (ICW) where (T) value was (6.181) with p-value (0.001), the mean of (Male) (36.43) and the mean of (Female) (33.36) for the benefit of the male sample.

- There was a highly significant difference at pvalue (0.01) between (Male) and (Female) for $(\mathrm{AL})$ where $(\mathrm{T})$ value was (4.448) with p-value (0.001), the mean of (Male) (73.65) and the mean of (Female) (69.38) for the benefit of the male sample.

- There was a highly significant difference at pvalue (0.01) between (Male) and (Female) for (IMW $1^{\text {ST }}$ ) where $(\mathrm{T})$ value was $(9.343)$ with $\mathrm{p}$ value (0.001), the mean of (Male) (55.07) and the mean of (Female) (49.61) for the benefit of the male sample.

- There was a highly significant difference at pvalue (0.01) between (Male) and (Female) for (IMW $2^{\mathrm{ND}}$ ) where (T) value was (6.796) with pvalue (0.001), the mean of (Male) (61.77) and the mean of (Female) (55.29) for the benefit of the male sample.

- There was non-significant difference at p-value (0.05) between (Male) and (Female) for (ADM) where $(\mathrm{T})$ value was (1.182) with p-value $(0.3)$, the mean of (Male) (27.5) and the mean of (Female) (26.80).
- There was non-significant difference at p-value (0.05) between (Male) and (Female) for (ADD) where $(\mathrm{T})$ value was $(0.128)$ with $\mathrm{p}$-value $(0.4)$, the mean of (Male) (40.79) and the mean of (Female) (40.65).

Comparison between original arch length obtained from CBCT linear measurements and predicted arch length using Vaishnav's formula for North Gujarat population found that:

- In Male Sample: Predicted arch length (Vaishnav) was lower $($ Upper $=67.76 \pm 1.04 \mathrm{~mm})$ than Original Arch Length (Upper $=73.65 \pm 3.33$ $\mathrm{mm}$ ) and predicted arch length (Vaishnav) was higher $($ Lower $=69.12 \pm 1.78 \mathrm{~mm})$ than Original Arch Length $($ Lower $=64.2 \pm 3.69 \mathrm{~mm})$. Statistically, significant difference was present between Predicted arch length and Vaishnav Arch Length in upper and lower arch in males $(\mathrm{P} \leq 0.01)$.

- In Female Sample: Predicted arch length (Vaishnav) was lower (Upper $=66.40 \pm 0.58$ $\mathrm{mm})$ than Original Arch Length $($ Upper $=69.38$ $\pm 4.07 \mathrm{~mm}$ ) and predicted arch length (Vaishnav) was higher $($ Lower $=67.37 \pm 1.03 \mathrm{~mm})$ than Original Arch Length (Lower $=60.39 \pm$ $4.00 \mathrm{~mm}$ ) Arch Length. Statistically, significant difference was present between Predicted arch length and Vaishnav Arch Length in upper and lower arch in females $(\mathrm{P} \leq 0.01)$.

Comparison between original arch length obtained from CBCT linear measurements and predicted arch length using Paulino's formula found that:

- In Male Sample: Predicted arch length (Paulino) was higher $($ Upper $=78.94 \pm 3.23 \mathrm{~mm})$ (Lower $=67.27 \pm 3.22 \mathrm{~mm}$ ) than Original Arch Length $($ Upper $=73.65 \pm 3.3 \mathrm{~mm})($ Lower $=$ $64.2 \pm 3.69 \mathrm{~mm}$ ) in both the arches. Statistically, significant difference was present between Predicted arch length and original Arch Length in upper and lower arch in males $(\mathrm{P} \leq 0.01)$. 
- In Female Sample: Predicted arch length (Paulino) was higher $($ Upper $=74.76 \pm 1.75$ $\mathrm{mm})($ Lower $=64.12 \pm 1.87 \mathrm{~mm})$ than Original Arch Length (Upper $=74.76 \pm 1.75 \mathrm{~mm})$ (Lower $=60.39 \pm 4.00 \mathrm{~mm}$ ) in both the arches.
Statistically, significant difference was present between Predicted arch length and original Arch Length in upper and lower arch in females $(\mathrm{P} \leq 0.01)$.

TABLE (2): ICW and AL with Simple regression analysis in Mandible

\begin{tabular}{|c|c|c|c|c|c|c|c|c|}
\hline Model & B & SE & $\mathbf{R}$ & $\mathbf{R}^{2}$ & Adjusted $\mathbf{R}^{2}$ & $\mathbf{F}$ & $\mathbf{t}$ & p-value \\
\hline (Constant) & 16.235 & 2.779 & \multirow{2}{*}{0.909} & \multirow{2}{*}{0.827} & \multirow{2}{*}{0.824} & \multirow{2}{*}{276.623} & 5.842 & 0.000 \\
\hline ICW & 1.725 & 0.104 & & & & & 16.632 & 0.000 \\
\hline
\end{tabular}

Statistically, significant correlation was present between ICW and AL in lower arch with $R=0.909$ and $R^{2}=0.827(P \leq 0.01)$.

So, our study formula to predict Lower Arch Length $=16.235+1.725($ ICW $)$.

TABLE (3): ICW and AL with Simple regression analysis in Mandible according to Gender

\begin{tabular}{|c|c|c|c|c|c|c|c|c|c|}
\hline Gender & Model & B & SE & $\mathbf{R}$ & $\mathbf{R}^{2}$ & Adjusted $\mathbf{R}^{2}$ & $\mathbf{F}$ & $\mathbf{T}$ & p-value \\
\hline \multirow{2}{*}{ Male } & (Constant) & 23.485 & 2.918 & \multirow{2}{*}{0.935} & \multirow{2}{*}{0.875} & \multirow{2}{*}{0.871} & \multirow{2}{*}{195.951} & 8.047 & 0.000 \\
\hline & ICW & 1.461 & 0.104 & & & & & 13.998 & 0.000 \\
\hline \multirow{2}{*}{ Female } & (Constant) & 7.484 & 5.742 & \multirow{2}{*}{0.913} & \multirow{2}{*}{0.833} & \multirow{2}{*}{0.828} & \multirow{2}{*}{140.128} & 1.303 & 0.2 \\
\hline & ICW & 2.659 & 0.225 & & & & & 11.838 & 0.000 \\
\hline
\end{tabular}

Statistically, significant correlation was present between ICW and AL in lower arch for males with $R=0.935$ and $R^{2}=0.913$ $(P \leq 0.01)$. So, our study formula to predict Lower Arch Length $=23.485+1.461($ ICW).

Statistically, significant correlation was present between ICW and AL in upper arch for females with $R=0.913$ and $R^{2}=$ 0.833 (P $\leq 0.01)$. So, our study formula to predict lower Arch Length $=7.484+2.659$ (ICW).

Correlation between ICW and AL depicted greater in Males as compared to Females in Mandible.

\section{MAXILLA}

TABLE (4): ICW and AL with Simple regression analysis in Maxilla

\begin{tabular}{|c|c|c|c|c|c|c|c|c|}
\hline Model & B & SE & $\mathbf{R}$ & $\mathbf{R}^{2}$ & Adjusted $\mathbf{R}^{2}$ & $\mathbf{F}$ & $\mathbf{t}$ & p-value \\
\hline (Constant) & 21.589 & 4.563 & \multirow{2}{*}{0.821} & \multirow{2}{*}{0.675} & \multirow{2}{*}{0.669} & \multirow{2}{*}{120.306} & 4.732 & 0.000 \\
\hline ICW & 1.431 & .130 & & & & & 10.968 & 0.000 \\
\hline
\end{tabular}

Statistically, significant correlation was present between $I C W$ and $A L$ in upper arch with $R=0.821$ and $R^{2}=0.675(P \leq 0.01)$.

So, our study formula to predict Upper Arch Length $=21.589+1.431($ ICW $)$. 
TABLE (5): ICW and AL with Simple regression analysis in Maxilla according to Gender

\begin{tabular}{|c|c|c|c|c|c|c|c|c|c|}
\hline Gender & Model & B & SE & $\mathbf{R}$ & $\mathbf{R}^{2}$ & Adjusted $\mathbf{R}^{2}$ & $\mathbf{F}$ & $\mathbf{t}$ & p-value \\
\hline \multirow{2}{*}{ Male } & (Constant) & 18.013 & 10.825 & \multirow{2}{*}{0.837} & \multirow{2}{*}{0.700} & \multirow{2}{*}{0.689} & \multirow{2}{*}{65.279} & 1.664 & 0.000 \\
\hline & ICW & 2.620 & 0.324 & & & & & 8.080 & 0.000 \\
\hline \multirow{2}{*}{ Female } & (Constant) & 33.287 & 5.860 & \multirow{2}{*}{0.794} & \multirow{2}{*}{0.630} & \multirow{2}{*}{0.617} & \multirow{2}{*}{47.639} & 5.680 & 0.1 \\
\hline & ICW & 1.108 & 0.161 & & & & & 6.902 & 0.000 \\
\hline
\end{tabular}

Statistically, significant correlation was present between ICW and AL in upper arch for males with $R=0.837$ and $R^{2}=0.700$ $(P \leq 0.01)$. So, our study formula to predict Upper Arch Length $=18.013+2.620($ ICW $)$.

Statistically, significant correlation was present between ICW and AL in upper arch for females with $R=0.794$ and $R^{2}=$ 0.913 (P $\leq 0.01)$. So, our study formula to predict Upper Arch Length $=33.287+1.108($ ICW).

Correlation between ICW and AL depicted greater in Males as compared to Females in Maxilla.

\section{DISCUSSION}

Our measurements were obtained from CBCT slices, as linear measurements taken from CBCT images have been shown to be accurate, sensitive and reliable in many prior studies when compared to conventional real measurements. ${ }^{[22,23]}$ there are also no clinical differences between measurements taken with the CBCT technique and those taken with digitalized plaster models utilizing the Digital Method (2D).$^{[7]}$

Parak et al 2020 ${ }^{[5]}$ evaluated the reliability, reproducibility and validity of the arch length and arch length discrepancy in each digital relative to a plaster model. They concluded that the measurements based on the digital program revealed high reliability, reproducibility and accurate than conventional measurement

In our study we assessed 60 cases, 30 males and 30 females, the sample size comparatively larger than similar study for prediction of arch length conducted on model cast ${ }^{[14]}$ and larger than another study where arch measurements obtained from CBCT cuts $^{[8]}$

In the present study, subjects with age between 18-25 years were selected because the growth and width of dental arch are completed and also, to exclude the effect of attrition of enamel occurring with age which may affect the enamel thickness or teeth sizes measurements. ${ }^{[24-26]}$

Our results regarding upper and lower arch measurements including ICW, ISMW and upper IMW measurements showed high significant differences between males and females with greater values in males more than females, Which determines the significance of these measurements as valuable determinant parameter for differentiation between males and females (table 1)

Many studies coincide with our results using several methods for arch measurements as using digital caliper on cast ${ }^{[27,28]}$ or directly on oral cavity, stereomicroscope $\mathrm{e}^{[29,30]}$ and 3D CBCT mode $\mathrm{l}^{[8,24]}$.

Moreover, males' values of both arch measurements exceed females' with high significant differences except for lower IMW, where there was non-significant difference between males and females but still males' values are more than females'. This result concerning lower IMW agree with that of Vaishnav et al. who found that there was no significant differences in IMW between males and females and they depicted greater ICW and IMW in males as compared to females in both arches with maxillary inter-molar arch width being more significant. 
Rao et al. ${ }^{[31]}$ and Deniel ${ }^{[32]}$ determine the role of ICW and IMW in identification of sex of individuals and they found that these measurements for males were higher than females in both maxilla and mandible from which we could conclude that ICW and IMW can be used as a tool in gender determination.

On the other hand, our results on upper and lower arch measurements including ADM and ADD showed non-significant differences between males and females but still males' values slightly larger than females'.

Results of the current study concerning the comparison between original arch length obtained from CBCT measurements and predicted arch length using formulas stated by Vaishnav et al. showed that there were statistically significant differences between original and predicted arch length in both upper and lower jaws. Likewise, the comparison between original arch length obtained from CBCT measurements and predicted arch length using formula given by Paulino V. et al. showed that there were statistically significant differences between original and predicted arch length of all cases with higher values in predicted arch length than original arch length.

From these results, we could conclude that both regression equation formulas given by Vaishnav et al. and Paulino V. et al. are not reliable for arch length prediction in Egyptian population. Variation of arch width and measurements between different population were proved by many authors before ${ }^{[27,28,33,34]}$

Prasad et al. 2013 ${ }^{[34]}$ and Omar et al. 2018 ${ }^{[28]}$ concluded that variation of arch widths and measurements according to race, ethnicity and gender necessitate utilizing specific orthodontic arch wire according to pre-treatment arch shape and width for every patient.

Although, our results were not in concurrence with formulas given by Vaishnav et al. and Paulino V. et al. they found a high correlation coefficient between AL and ICW for both arches which is the same results reached by this study, as there was statistically significant correlation between ICW and $\mathrm{AL}$ in mandible $(\mathrm{R}=0.909$ and $\mathrm{R} 2=0.827 \mathrm{P} \leq$ $0.01)$ and in maxilla with $(\mathrm{R}=0.821$ and $\mathrm{R} 2=0.675$ $\mathrm{P} \leq 0.01)$ in both males and females.

There were many studies showed the correlation between measurements of arch width using dental cast $^{{ }^{[35-37]}}$ the highest correlation was between $\mathrm{AL}$ and ICW in both arches concluding that changes in one magnitude could change the other. ${ }^{[14-16,38]}$

Our results couldn't be compared with those of Germane et al. ${ }^{[35]}$ where those authors found a correlation in patients with post-orthodontic treatment while our patients were have normal occlusion and don't experienced with orthodontic treatment before.

Motoyashi et al. ${ }^{[36]}$ also found that, the increase in arch perimeter as a result of intermolar mandibular growth, on the order of $0.37 \mathrm{~mm}$, which was higher than the 0.27 described by Germane et al. ${ }^{[35]}$

AL-Ansari et al ${ }^{[16]}$ found strong correlation between inter-canine width, inter-molar width, and arch length in the mandibular arch.

Sanin et $\mathbf{a l}^{[37]}$ found that dental arch width and length had a direct, strong relationship with the dental arch perimeter. They developed the following regression equation to predict arch length and perimeter: Arch perimeter $=($ dental arch width $\times 0.504)+($ dental arch length $\times 1.525)+14.856$.

Very few studies were conducted to predict AL based on ICW using model cast, unlike the previous studies, the results of current study provide new base line regression equation formulas to predict arch length based on inter-canine width for Egyptian population using CBCT images for both gender males and females and for maxilla and mandible of each gender. 


\section{CONCLUSION}

According to this study, CBCT scanning allows us to assess arch measurements, therefore, CBCT will solve the problem of record keeping and direct measurements of dental arch for analysis are possible from digital image. Moreover, Arch measurements based on CBCT imaging show highly significant gender difference.

The significant results reveled that both regression equations are not reliable to be used in Egyptian population.. A new regression equation formula is developed for maxillary and mandibular arches of all patients:

$$
\text { Upper Arch Length }=21.589+1.431(\mathrm{ICW}) \text {. }
$$$$
\text { Lower Arch Length }=16.235+1.725(\mathrm{ICW}) \text {. }
$$

Regression equation formulas are developed for male's maxillary and mandibular arches: Upper Arch Length $=18.013+2.620(\mathrm{ICW})$.

Lower Arch Length $=23.485+1.461(\mathrm{ICW})$.

Regression equation formulas are developed for female's maxillary and mandibular arches: Upper Arch Length $=33.287+1.108(\mathrm{ICW})$.

Lower Arch Length $=7.484+2.659$ (ICW).

\section{RECOMMENDATION}

Further investigation on the validity of the new regression equation could be done one large sample of Egyptian population

\section{REFERENCES}

1. Redlich, M., et al., A new system for scanning, measuring and analyzing dental casts based on a 3D holographic sensor. Orthod Craniofac Res, 2008. 11(2): p. 90-5.

2. Wiranto, M.G., et al., Validity, reliability, and reproducibility of linear measurements on digital models obtained from intraoral and cone-beam computed tomography scans of alginate impressions. Am J Orthod Dentofacial Orthop, 2013. 143(1): p. 140-7.

3. Crosby, D.R. and C.G. Alexander, The occurrence of tooth size discrepancies among different malocclusion groups. Am J Orthod Dentofacial Orthop, 1989. 95(6): p. 457-61.
4. Schirmer, U.R. and W.A. Wiltshire, Manual and computeraided space analysis: a comparative study. Am J Orthod Dentofacial Orthop, 1997. 112(6): p. 676-80.

5. Park, S.H., et al., Evaluation of the Reliability, Reproducibility and Validity of Digital Orthodontic Measurements Based on Various Digital Models among Young Patients. J Clin Med, 2020. 9(9).

6. Gamba, T.O., et al., Influence of cone-beam computed tomography image artifacts on the determination of dental arch measurements. Angle Orthod, 2014. 84(2): p. 274-8.

7. Tarazona, B., et al., A comparison between dental measurements taken from CBCT models and those taken from a digital method. Eur J Orthod, 2013. 35(1): p. 1-6.

8. Alam, M., et al., Tooth size and Dental arch Dimension measurement through Cone beam Computed Tomography: Effect of Age and Gender. Research Journal of Recent Sciences, 2014. 3: p. 2277-2502.

9. Park, C.-W., et al., Volumetric accuracy of cone-beam computed tomography. Imaging science in dentistry, 2017. 47(3): p. 165-174.

10. Harrell, W., 3D Diagnosis and Treatment Planning in Orthodontics. Seminars in Orthodontics, 2009. 15: p. 35-41.

11. Creekmore, T.D., et al., JCO roundtable: diagnosis and treatment planning. J Clin Orthod, 1992. 26(9): p. 585-606.

12. Zilberman, O., J. Huggare, and K.A. Parikakis, Evaluation of the validity of tooth size and arch width measurements using conventional and three-dimensional virtual orthodontic models. The Angle Orthodontist, 2003. 73(3): p. 301-306.

13. Hnat, W.P., et al., The relationship of arch length to alterations in dental arch width. Am J Orthod Dentofacial Orthop, 2000. 118(2): p. 184-8.

14. Vaishnav, D.S., D. Desai, and A. Kubavat, Reliability Of Predicted Arch Lenght Based on Measured Inter Canine Width And Sex Determination Using Measured Inter Canine Width And Inter Molar Width In North Gujarat Population July 2020 1594808286 3407659. 2020.

15. Paulino, V., et al., Prediction of arch length based on intercanine width. Eur J Orthod, 2008. 30(3): p. 295-8.

16. Al-Ansari, N.B., S.A. Abdul Ameer, and M. Nahidh, A New Method for Prediction of Dental Arch Perimeter. Clin Cosmet Investig Dent, 2019. 11: p. 393-397.

17. Taner, T.U., et al., Evaluation of dental arch width and form changes after orthodontic treatment and retention 
with a new computerized method. Am J Orthod Dentofacial Orthop, 2004. 126(4): p. 464-75; discussion 475-6.

18. Aluko, I.A., O. Dacosta, and M. Isiekwe, Dental arch widths in the early and late permanent dentition of a Nigerian population. Nigerian Dental Journal, 2010. 17.

19. Al-Zubair, N., Determinants factors of Yemeni dental arch forms. Journal of Orthodontic Research, 2014. 2: p. 55.

20. Ward, D., et al., Changes in arch width. A 20-year longitudinal study of orthodontic treatment. The Angle orthodontist, 2006. 76: p. 6-13.

21. Islam, M.M. and M.Z. Hossain, A Comparative Study of Arch Widths of Bangladeshi Subject with Normal Occlusion and Class II Division 1 Malocclusion. Bangladesh Journal of Orthodontics and Dentofacial Orthopedics, 2013. 2.

22. Kopp, S. and P. Ottl, Dimensional stability in composite cone beam computed tomography. Dentomaxillofac Radiol, 2010. 39(8): p. 512-6.

23. Tarazona-Álvarez, P., et al., Comparative study of mandibular linear measurements obtained by cone beam computed tomography and digital calipers. J Clin Exp Dent, 2014. 6(3): p. e271-4.

24. Salam, E., A. Khalifa, and D. Hassouna, Odontometric analysis using CBCT for sexual dimorphism in EgyptianFayoum population in case of normal occlusion. Egyptian Dental Journal, 2021.67(2): p. 1319-1332.

25. Brannon, R.B. and H.P. Kessler, Problems in mass-disaster dental identification: a retrospective review. J Forensic Sci, 1999. 44(1): p. 123-7.

26. Reddy, R., et al., Odontometrics: A Key to Gender Determination. World Journal of Dentistry, 2016. 7: p. 150-154.

27. Ling, J.Y. and R.W. Wong, Dental arch widths of Southern Chinese. Angle Orthod, 2009. 79(1): p. 54-63.

28. Omar, H., et al., Dental arch dimensions, form and tooth size ratio among a Saudi sample. Saudi medical journal, 2018. 39(1): p. 86-91.
29. Al-Khatib, A.R., et al., Tooth size and dental arch dimensions: a stereophotogrammetric study in Southeast Asian Malays. Orthod Craniofac Res, 2011. 14(4): p. 243-53.

30. Shahid, F., et al., Geomorphometrics of Tooth Size and Arch Dimension Analysis by Conventional Digital Caliper and Digital Stereomicroscope to Establish Standard Norms for the Pakistani Population. Journal of Hard Tissue Biology, 2015. 24: p. 155-168.

31. Rao, G. and G. Kiran, Sex Determination by means of Inter-Canine and Inter-Molar Width- A Study in Telangana population. Asian Pacific Journal of Health Sciences, 2016.3: p. 171-175.

32. Daniel, M.J., et al., Comparison of inter-canine and intermolar width as an aid in gender determination: A preliminary study. Journal of Indian Academy of Forensic Medicine, 2014. 36: p. 168-172.

33. Sakamoto, T., A study on the developmental changes of dentofacial complex of Japanese with special reference to Sella Turica. J Jap Orthodont Soc, 1959. 18: p. 1-17.

34. Prasad, M., et al., Evaluation of arch width variations among different skeletal patterns in South Indian population. Journal of natural science, biology, and medicine, 2013. 4(1): p. 94-102.

35. Germane, N., et al., Increase in arch perimeter due to orthodontic expansion. American journal of orthodontics and dentofacial orthopedics : official publication of the American Association of Orthodontists, its constituent societies, and the American Board of Orthodontics, 1991. 100: p. 421-7.

36. Motoyoshi, M., et al., An experimental study on mandibular expansion: Increases in arch width and perimeter. European journal of orthodontics, 2002. 24: p. 125-30.

37. Sanin, C., et al., Arc Length of the Dental Arch Estimated by Multiple Regression. Journal of dental research, 1970. 49: p. 885 .

38. Soni, D.V., Using Inter-canine Width for Arch Length Prediction in Jaipur Population. IOSR Journal of Dental and Medical Sciences, 2013. 7: p. 21-23. 